\section{Commentary: An innovative, minimally-invasive approach to post-pneumonectomy bronchopleural fistula}

\author{
Irmina A. Elliott, MD, ${ }^{\mathrm{a}}$ Harmeet S. Bedi, MD, ${ }^{\mathrm{b}}$ and \\ Natalie S. Lui, MD
}

In this issue of the Journal, Menezes and colleagues ${ }^{1}$ present a case of a bronchopleural fistula (BPF) in a patient presenting 2 months after left pneumonectomy with a chronic cough without signs of infection and an air-fluid level in the left chest. ${ }^{1}$ The patient had previously received immunotherapy (but not radiation), and the bronchial stump had been buttressed with an intercostal muscle flap intraoperatively. The BPF was successfully closed bronchoscopically using an Amplatzer vascular plug II (AVP).

The AVP is a braided nitinol mesh plug first designed for atrial septal closure and now often used in interventional radiology for embolization of bleeding; the device costs on the order of $\$ 1000 .^{2}$ The available diameters, lengths, and small guide catheters used to deploy the plug are well suited to bronchoscopic use. Use of the AVP is among a host of minimally invasive techniques that have been successfully used to treat postoperative BPFs. ${ }^{3}$ These include application of products or use of devices such as fibrin glue, coils, valves, and even carbolic acid. ${ }^{4,5}$ Covered stent placement spanning the trachea to the contralateral mainstem bronchus to exclude the bronchial stump is also an option, ${ }^{6}$ although seating the stent can be challenging. Because this complication is rare, data to support any specific approach will likely remain limited to case series.

\footnotetext{
From the ${ }^{\mathrm{a} D e p a r t m e n t}$ of Cardiothoracic Surgery and ${ }^{\mathrm{b}}$ Division of Pulmonary and Critical Care Medicine, Department of Medicine, Stanford University School of Medicine, Stanford, Calif.

Disclosures: The authors reported no conflicts of interest.

The Journal policy requires editors and reviewers to disclose conflicts of interest and to decline handling or reviewing manuscripts for which they may have a conflict of interest. The editors and reviewers of this article have no conflicts of interest.

Received for publication Aug 12, 2020; revisions received Aug 12, 2020; accepted for publication Aug 13, 2020; available ahead of print Aug 15, 2020.

Address for reprints: Natalie Lui, MD, 300 Pasteur Dr, Falk Bldg, CVRB MC 5407, Stanford, CA 94305 (E-mail: natalielui@stanford.edu).

JTCVS Techniques 2020;4:351-2

2666-2507

Copyright (C) 2020 The Authors. Published by Elsevier Inc. on behalf of The American Association for Thoracic Surgery. This is an open access article under the CC BY-NCND license (http://creativecommons.org/licenses/by-nc-nd/4.0/).

https://doi.org/10.1016/j.xjtc.2020.08.032
}

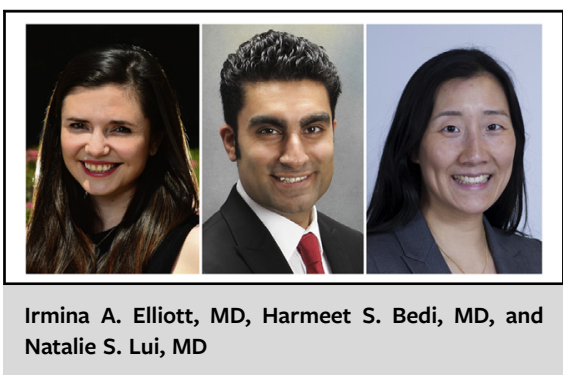

CENTRAL MESSAGE

Creative bronchoscopic techniques, such as occlusion with an Amplatzer vascular plug, should be considered in the management of postoperative bronchopleural fistula in carefully selected patients.

One concern about any technique requiring insertion of a device through the BPF is further injury or expansion of the fistula. This is especially concerning for smaller BPFs that might be difficult to visualize and access. For this reason, we urge caution when considering this technique and advise collaborating with an interventionalist with the AVP experience to assist in the case.

It also should be noted that foreign bodies in the airway can cause significant granulation tissue. The production of granulation tissue is unpredictable and very patientspecific; some patients can develop bulky granulation tissue within 4 weeks, whereas others never do. For this reason, the length of the bronchial stump should be taken into consideration when planning bronchoscopic intervention. In a patient with a very short left mainstem stump, any granulation tissue could easily lead to right mainstem obstruction, in the same way that patients can develop mainstem obstruction from granulation originating from a stent located in the contralateral mainstem bronchus. If this were to occur in a patient with a BPF, removing the plug might not be an option.

Collaboration with an interventionalist experienced in use of the chosen device, as well as careful consideration of the anatomy, including size of the fistula, stump length, and relation to the trachea and contralateral bronchus, are critical for planning minimally invasive management of BPFs. Patients with a postoperative BPF and signs of sepsis who are reasonable surgical candidates are probably still best managed with aggressive surgical debridement, closure, and tissue flap 
coverage. However, in patients with a more indolent clinical presentation, or those who are too deconditioned to undergo surgery, creative minimally invasive approaches should be considered to minimize the morbidity associated with reoperation.

We congratulate the authors on an innovative and successful solution to a difficult clinical problem.

\section{References}

1. Menezes V, Soder S, Kadadah S, Masson JB, Lafontaine E, Liberman M. Bronchoscopic treatment of a bronchopleural fistula after pneumonectomy. J Thorac Cardiovasc Surg Tech. 2020;4:345-8.
2. Lopera JE. The Amplatzer vascular plug: review of evolution and current applications. Semin Intervent Radiol. 2015;32:356-69.

3. Fruchter O, Bruckheimer E, Raviv Y, Rosengarten D, Saute M, Kramer MR. Endobronchial closure of bronchopleural fistulas with Amplatzer vascular plug. Eur J Cardiothorac Surg. 2012;41:46-9.

4. Cardillo G, Carbone L, Carleo F, Galluccio G, Di Martino M, Giunti R, et al. The rationale for treatment of postresectional bronchopleural fistula: analysis of $52 \mathrm{pa}-$ tients. Ann Thorac Surg. 2015;100:251-7.

5. Wang Z, Yu HB, Luo Q, Liu YY. Treatment of bronchopleural fistula with carbolic acid instilled through a bronchofiberscope in post-pulmonectomy patients. J Cardiothorac Surg. 2015;10:120.

6. Andreetti C, D'Andrilli A, Ibrahim M, Ciccone AM, Maurizi G, Mattia A, et al. Effective treatment of post-pneumonectomy bronchopleural fistula by a conical fully covered self-expandable stent. Interact Cardiovasc Thorac Surg. 2012;14: 420-3. 